\title{
NUMERICAL ANALYSIS OF A RADIANT HEAT FLUX CALIBRATION SYSTEM
}

\author{
Shanjuan Jiang \\ Department of Mechanical and Aerospace Engineering \\ University of California, Los Angeles, CA 90095
}

\author{
Thomas J. Horn \\ National Aeronautics and Space Administration \\ Dryden Flight Research Center \\ Edwards, California
}

\author{
V. K. Dhir \\ Department of Mechanical and Aerospace Engineering \\ University of California, Los Angeles, CA 90095
}

\begin{abstract}
A radiant heat flux gage calibration system exists in the Flight Loads Laboratory at NASA's Dryden Flight Research Center. This calibration system must be well understood if the heat flux gages calibrated in it are to provide useful data during radiant heating ground tests or flight tests of high speed aerospace vehicles. A part of the calibration system characterization process is to develop a numerical model of the flat plate heater element and heat flux gage, which will help identify errors due to convection, heater element erosion, and other factors.

A 2-dimensional mathematical model of the gage-plate system has been developed to simulate the combined problem involving convection, radiation and mass loss by chemical reaction. A fourth order finite difference scheme is used to solve the steady state governing equations and determine the temperature distribution in the gage and plate, incident heat flux on the gage face, and flat plate erosion. Initial gage heat flux predictions from the model are found to be within $\pm 7 \%$ of experimental results.
\end{abstract}

\section{NOMENCLATURE}

\section{$\mathrm{A}=$ area}

$\mathrm{Bh} \quad=$ blowing parameter

$\mathrm{Cp} \quad=$ specific heat

$\mathrm{D}=$ diameter of the heat flux gage

DI = channel diameter

$D_{12} \quad=$ oxygen diffusion coefficient

$\mathrm{F} \quad=$ shape factor

Gr $\quad$ Grashof number

g = acceleration due to gravity

$\mathrm{H} \quad=$ height

$\mathrm{h}$ = average natural convection heat transfer coefficient

$1=$ electrical current through the graphite plate

$\mathrm{k}=$ thermal conductivity

$\mathrm{L} \quad=$ length

$Q^{\prime \prime} \quad=$ heat generation per unit volume of graphite plate

q $\quad=$ heat flux

$\mathrm{m}_{1, \quad} \quad=$ oxygen mass concentration near the graphite plate surface

$\mathrm{m}_{1 . x} \quad=$ oxygen mass concentration in the ambient air

$\dot{m}^{n} \quad$ = mass transfer rate from horizontal graphite plate surface

$\mathrm{n}_{1 \cdot x} \quad=$ oxygen mass flux near the graphite plate surface

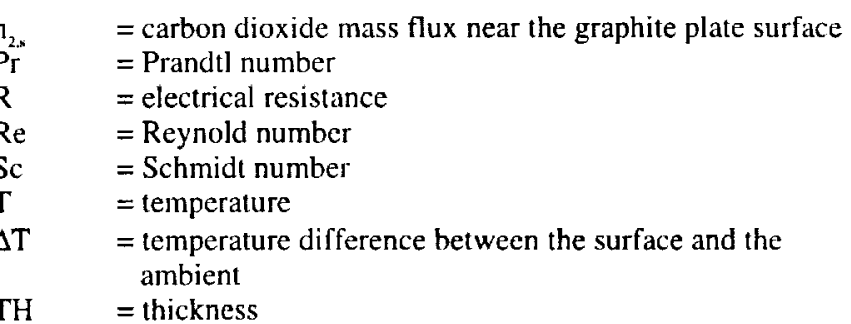

Greek letters:

$\begin{array}{ll}\beta_{1 \mathrm{~m}} & =\text { mass transfer driving force } \\ \varepsilon & =\text { radiation emissivity } \\ \eta & =\text { mass transfer conductance } \\ \eta_{c} & =\text { mass transfer conductance } \\ \lambda & =\text { specific resistance } \\ v & =\text { kinematic viscosity } \\ \rho & =\text { density of the graphite plate } \\ \sigma & =\text { Stefan-Boltzmann constant } \\ \varphi & =\text { Prandt] number function }\end{array}$

Subscripts:

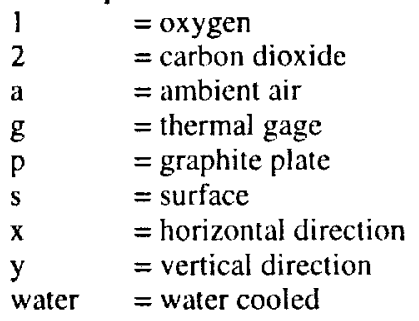

Superscripts:

$\begin{array}{ll}0 & =\text { zero mass transfer } \\ \mathrm{d} & =\text { heated plate facing down } \\ \mathrm{u} & =\text { heated plate facing up }\end{array}$




\section{INTRODUCTION}

Uncertainties in radiant heat flux gage calibrations are typically assumed to be on the order of $\pm 10 \%$. The National Institute of Standards and Technology (NIST) is currently working to significantly reduce this uncertainty at heat flux levels up to 200 $\mathrm{kW} / \mathrm{m}^{2}$ as described in Holmberg(1997); Grosshandler(1997); Murthy(1997). However, aerodynamic heating in hypersonic flight can generate heat flux levels well in excess of this level. The Flight Loads Laboratory (FLL) at NASA's Dryden Flight Research Center performs radiant thermal-structural tests on aerospace vehicle structures which represent aerodynamic heat fluxes up to 1,100 $\mathrm{kW} / \mathrm{m}^{2}$. This paper describes a numerical analysis which is part of an effort undertaken in the FLL to reduce radiant heat flux calibration uncertainties at heat fluxes up to $1,100 \mathrm{~kW} / \mathrm{m}^{2}$.

A radiant heat flux gage calibration system in the FLL uses an electrically heated graphite plate as a heat source (A detailed description is given by horn(1993)). The main objective of the project described in this paper is to numerically model the flat plate heater and compare numerical and experimental results in an effort to quantify and, if possible, reduce errors in the calibration system. An initial 2-dimensional model of the system has been developed and the results have been compared to data from experiment. The numerical model provides the temperature distribution in both the graphite plate and the heat flux gage as well as the heat flux at the gage face. The finite difference method was used in the numerical model. The boundary conditions on the front face of the heat flux gage include heat received by radiation from the graphite plate and lost to the ambient atmospherc by natural convection. Heat transfer by forced convection of water is modeled on the back face of the gage. Heat is transferred from the graphite plate by natural convection and radiation to the ambient surroundings as well as the heat flux gage on one side of the plate. Also, oxidation of the graphite plate, which impacts radiation view factors, is included in the model.

\section{EXPERIMENT}

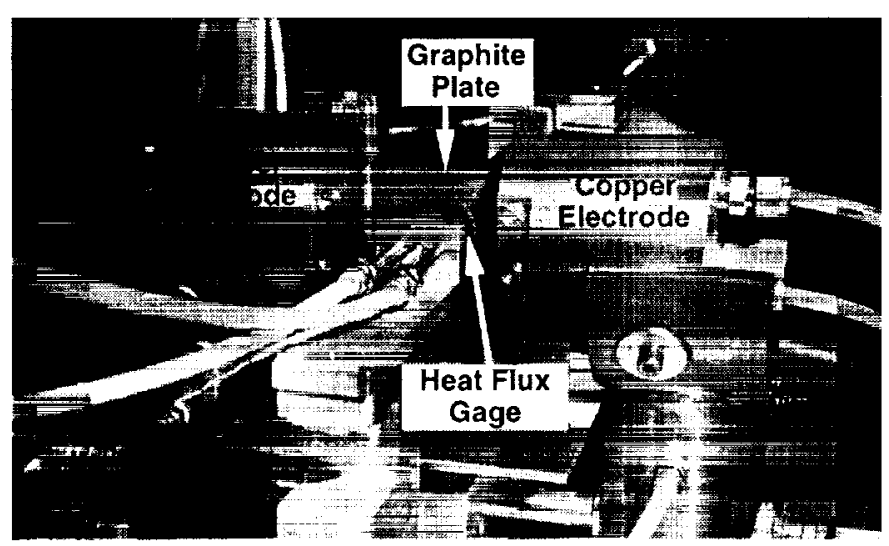

Figure 1: Heat Flux Calibration System, Side View

The heat flux gage calibration system in the Flight Loads Laboratory at NASA $S$ Dryden Flight Research Center consists of a graphite plate clamped between two copper clectrodes (see Fig. 1). The graphite plate undergoes olmuc heating as low voltage $(<24$ volts), high curren! rup to 2400 Amps), electric power is passed through the plate. Thi plate can reach temperitures up to $2800^{\circ} \mathrm{C}$.
Calibrations can be transferred from one heat flux gage to another by placing one heat flux gage on each side of the graphite plate, as shown in Fig. 2. The heat generation is assumed to be uniform.

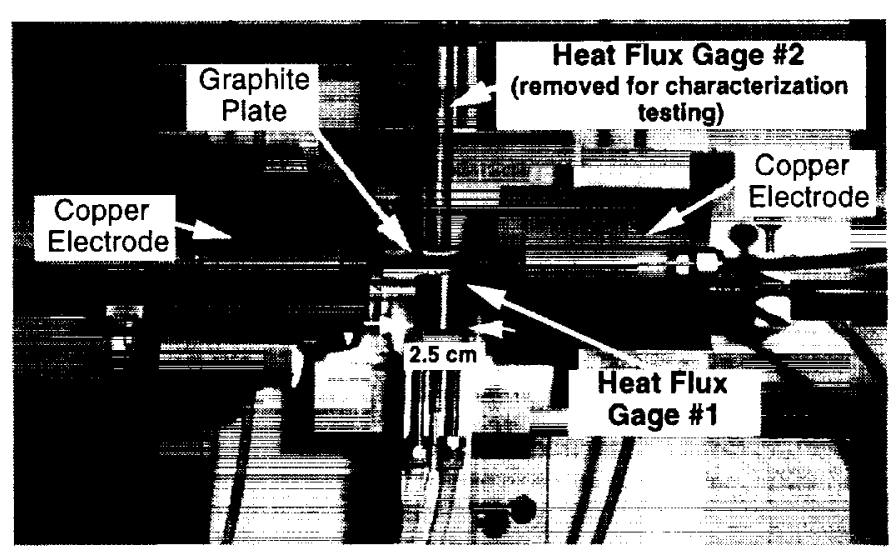

Figure 2: Heat Flux Calibration System, Top View

The experiments performed to support the characterization of the

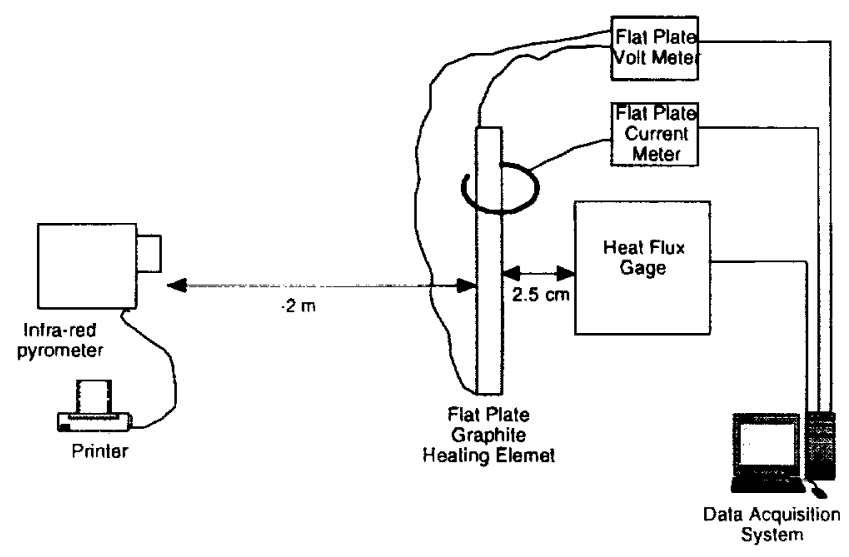

Figure 3: Characterization Test System Schematic

flat plate heater utilized a circular foil heat flux gage to measure heat flux. The calibration supplied by the gage manufacturer was used. The second heat flux gage was eliminated. Other measurements include surface temperature, voltage across the plate, current through the plate, and plate erosion.

An infra-red pyrometer, described by Matthews(1989), measured plate surface temperature at the center of the clear side of the plate (Fig. 3). The target spot size was approximately $1 \mathrm{~cm}$ diameter. The pyrometer uses a laser based technique to measure emissivity and compute a temperature corrected for emissivity. It also incorporates through-the-lens sighting to aid in aiming and focusing the pyrometer optics on the measurement location. A wire mesh grid placed over the flat graphite plate provided features on which to aim and focus. The grid was removed prior to testing.

Voltage was measured at the copper electrodes. Electric current passing through the plate was measured as well. The voltage, current, and heat flux data were acquired on a personal computer based data 
acquisition system using voltmeters, a GPIB interface, and associated data acquisition software. Temperature data was logged every 10 seconds on board the infra-red pyrometer and printed out after each test. Plate thickness was measured at the center of the plate using a micrometer before and after each test. Erosion of the top and bottom of the plates were measured post-test using a taper gage and flat surface.

Tests were performed at nominal heat fluxes of $100 \mathrm{~kW} / \mathrm{m}^{2}, 200$ $\mathrm{kW} / \mathrm{m}^{2}, 350 \mathrm{~kW} / \mathrm{m}^{2}$, and $450 \mathrm{~kW} / \mathrm{m}^{2}$. A test was run for $2,4,6,8$, and 10 minutes for each nominal heat flux. This matrix allowed the acquisition of voltage, current, and plate erosion data as a function of heat flux (i.e., plate temperature) and run time. The experimental data presented in this paper were obtained during the nominal $450 \mathrm{~kW} / \mathrm{m}^{2}$, 10 minute run.

A typical test proceeds as follows:

I. Measure thickness of a new graphite plate

2. Install the plate between the copper electrodes. The four set screws visible in Fig. 1 secure the plate and are uniformly torqued using a torque limiting screwdriver.

3. Apply minimum power to the flat plate and visually check for uniform heating as the plate begins to glow.

4. Remove power from plate. Retorque set screws and recheck plate heating or proceed to next step as required.

5. Start data acquisition and recording

6. Apply power to the plate by setting the manual power supply control to the predetermined level which corresponds to the desired nominal heat flux.

7. Continue power application for the desired length of time without readjusting the manual power supply control.

8. Remove power from the plate when desired run time has been reached.

9. Remove graphite plate from between the clecirodes.

10. Measure eroded plate thickness as well as top and bottom erosion.

Some additional remarks are necessary regarding steps 3,6 and 7 above. Some small amount of erosion occurs when the plate is checked for uniform heating (step 3 above). The minimum power possible is used for this run and the total energized time is less than I minute. The erosion caused in step 3 is extremely small and cannot be measured without disturbing the test setup, which would introduce still more errors into the heat flux measurement.

The nominal heat flux values mentioned earlier are only target values. The resolution of the manual power supply control allows the target heat flux to be set within $30 \mathrm{~kW} / \mathrm{m}^{2}$ in step 6 . For this reason, the heat flux data presented in this report will differ slightly from the nominal, or target, value.

Step 7, above, indicates that the manual power supply control is not adjusted once it is set for the desired heal flux. The constant power supply setting and plate erosion result in significant decrease in the measured heat flux (up to $20 \%$ ) and flat plate current (up to $32 \%$ ) while causing a voltage increase of up to $5 \%$.

\section{NUMERICAL MODELING}

The numerical model developed in this study includes conduction heat transfer within the graphite plate and heat flux gage model, heat generation within the graphite platc, and convective, radiative, and mass transfer boundary condilions. A schematic diagram of the experiment set-up is shown in Fig. 4. The numerical model represents a vertical plane which passes through the flat plate and heat hux gage midway between the electrodes (the hatched lines). Figure 5. shows the configuration used in this study to simulate the 2Dimensional model. This two dimensional model is being used to develop modeling techniques which incorporate the various physical phenomena and will be extended to three dimensions in the near future.

The problem is assumed to be quasi-steady state. That is, heat conduction within the graphite plate and heat flux gage is essentially steady state at any given moment in time even though the boundary conditions (i.e., current through the plate, mass loss, etc.) vary slowly with time. This assumption is implemented in the numerical model by using an implicit finite difference method to solve the two dimensional, steady state heat conduction equations at discrete time steps (1 second intervals). The mass loss from the graphite plate over 1 second is computed after each time step. The next time step conduction solution proceeds with new plate thickness and height, as determined from the previous mass loss calculation, and new current through the flat plate, as measured during the experiment.

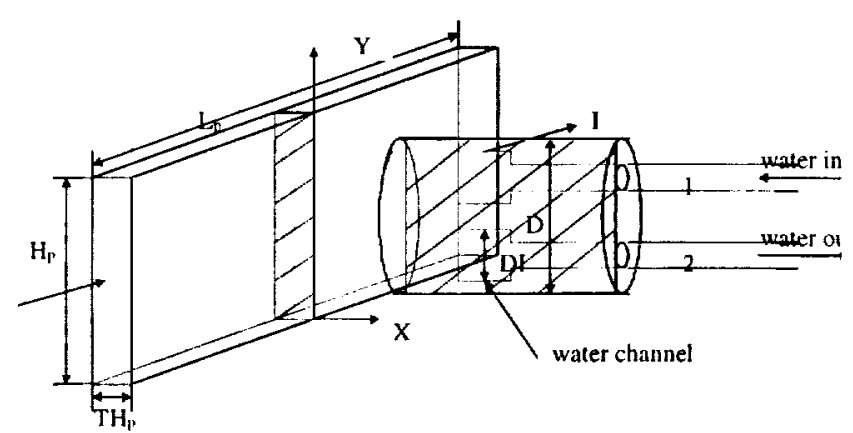

Figure 4: Schmematic of Flat Plate and Heat Flux Gage With The Computation Cross Section

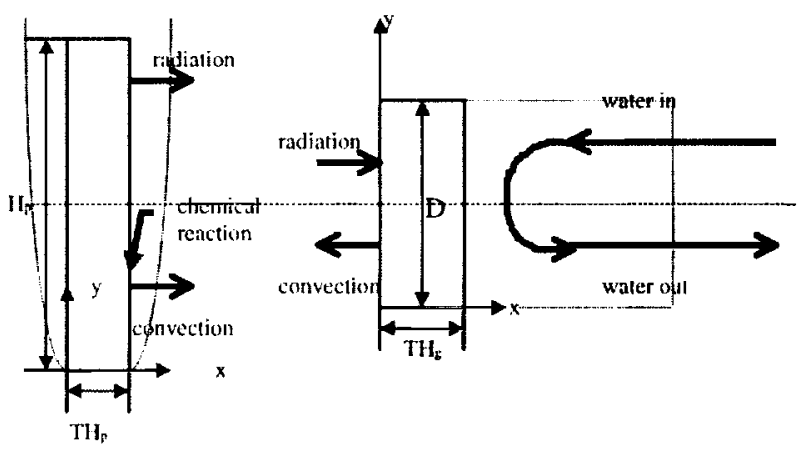

Figure 5: Computation Regime

\subsection{Numerical model for the graphite plate}

As shown in Fig. 5, the length of the plate is $L_{p}$, the height is $H_{r}$, and the thickness is $\mathrm{TH}_{\mathrm{r}}$. The steady state governing energy equation for the graphite plate is:

$$
\frac{\partial}{\partial x}\left(k_{p} \frac{\partial T}{\partial x}\right)+\frac{\partial}{\partial y}\left(k_{p} \frac{\partial T}{\partial y}\right)+Q=0
$$


where $k_{p}$ is the graphite plate thermal conductivity. Information provided by the graphite manufacturer indicates that the type ATJ graphite used in the plate is relatively isotropic. Therefore, the value used for $k_{p}$ is the same in both directions. The thermal conductivity of graphite steadily decreases from room temperature at $25^{\circ} \mathrm{C}$ to $3500^{\circ} \mathrm{C}$. The functional dependence is provided by the graphite plate vendor. The temperature dependence used in the numerical calculation is interpolated from the curve supplied by the vendor. The graphite plate is heated by passing electric current through it. The model incorporates this as a heat generation term, $Q^{m}$, as

$$
Q^{m}=\frac{I^{2} \cdot R}{L_{p} \cdot H_{p} \cdot T H_{p}}\left(W / m^{3}\right)
$$

where $I$ is the electrical current and $R$ is the electrical resistance in the direction of current flow. The resistance $R$ is calculated as

$$
R=\frac{\lambda \cdot L_{p}}{H_{p} \cdot T H_{p}}
$$

where $\lambda$ is the specific resistance. It is also a function of temperature. As shown in Fig. 6, it decreases from the room temperature at $25^{\circ} \mathrm{C}$ until around $500^{\circ} \mathrm{C}$ and thereafter it increases. At the final experimental temperature of $1840^{\circ} \mathrm{C}$, it has almost the same value as the one at room temperature. The temperature dependence employed in the numerical calculation is interpolated from the curve provided by the vendor and shown in Fig. 6 .

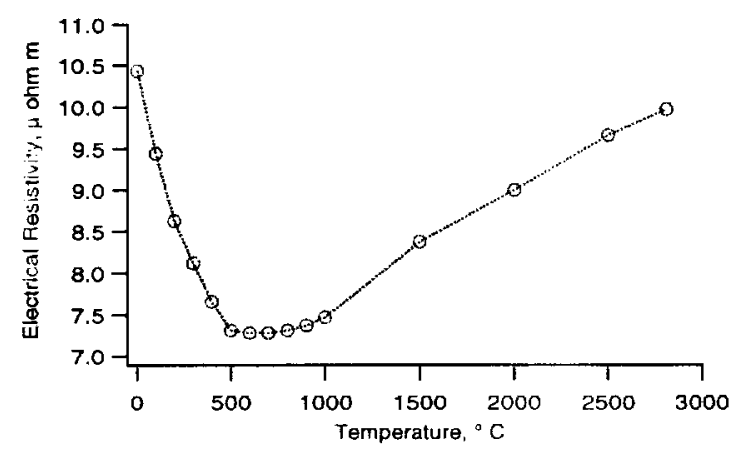

Figur، 6: ATJ Graphite Electrical Resistivity vs. Temperature

Th: boundary conditions employed in the model are:

$$
\begin{gathered}
y=H_{p} \quad ; \\
-k_{p} \frac{\partial T}{\partial y}=h_{c x}{ }^{\prime \prime} \cdot\left(T-T_{e}\right)+\sigma \cdot \varepsilon_{p} \cdot\left(T^{4}-T_{e}{ }^{4}\right)-\dot{m}_{x}{ }^{u \prime} \cdot \Delta H_{c} \\
y=0 \quad ; \\
-k_{p} \frac{\partial T}{\partial y}=h_{c x}{ }^{d} \cdot\left(T-T_{e}\right)+\sigma \cdot \varepsilon_{p} \cdot\left(T^{4}-T_{e}{ }^{4}\right)-\dot{m}_{x}{ }^{d l} \cdot \Delta H_{c} \\
x=0 \quad ; \\
-k_{p} \frac{\partial T}{\partial x}=\sigma \cdot \varepsilon_{p} \cdot\left(T^{4}-T_{e}^{4}\right)+h_{c y} \cdot\left(T-T_{e}\right)-\dot{m}_{y}^{\prime \prime} \cdot \Delta H_{c}
\end{gathered}
$$

$$
\begin{gathered}
x=T H_{p} ; \\
-k_{p} \frac{\partial T}{\partial x}=q_{p}+h_{c y} \cdot\left(T-T_{e}\right)-\dot{m}_{y}^{n} \cdot \Delta H_{c}
\end{gathered}
$$

At $y=0$, and $y=H_{n}$ heat is lost by radiation and natural convection and is generated by combustion. Eq. (4) and (5) represent this balance. At $x=0$, heat is lost by the radiation and convection to the ambient surroundings and gained because of the chemical reaction. At $x=T_{p}$, the boundary conditions include radiation and convection to the ambient surroundings as well as radiant exchange with the heat flux gage face. In Eq. (7), $q_{p}$ is the net radiation heat transfer out of the graphite plate surface. It consists of two parts, the net radiation heat flux from graphite plate to the gage $q_{p g}$ and the net radiation heat flux from graphite plate to the air $q_{p a}$. These heat fluxes are obtained as

$$
\begin{gathered}
q_{p g}=\frac{\sigma \cdot \varepsilon_{p} \cdot T_{p}^{4}-\sigma \cdot \varepsilon_{g} \cdot T_{g}^{4}}{\frac{1-\varepsilon_{p}}{\varepsilon_{p} \cdot A_{p}}+\frac{1}{A_{p} \cdot F_{p g}}+\frac{1-\varepsilon_{g}}{\varepsilon_{g} \cdot A_{g}}} \\
q_{p a}=\left(1-F_{p g}\right) \cdot \sigma \cdot \varepsilon_{p} \cdot\left(T_{p}^{4}-T_{a}^{4}\right)
\end{gathered}
$$

The shape factor $F_{p g}$ is calculated by doing the radiation network problem using a 2-D model introduced by Patankar(1989). It changes with the geometry of the graphite plate and the distance between the graphite plate and the gage.

In Eq. (4) and Eq. (5), $h_{c x}$ is the average natural convection coefficient for the horizontal plate surface

$$
h_{c x}=h_{c x}^{0} \frac{B_{h}}{\exp B_{h}-1}
$$

where the blowing parameter $B_{h}$ for heat transfer is defined as

$$
B_{h}=\frac{n_{1, x} C p_{1}+n_{2, s} C p_{2}}{h_{c x}{ }^{0}}
$$

In Eq. (10) heat transfer coefficient for zero mass transfer, $h_{c x}{ }^{0}$, for the heated plate facing up is obtained as

$$
h_{c x}^{0, u}=\frac{0.54 \cdot(G r \cdot \operatorname{Pr})^{1 / 4} \cdot k_{p}}{H_{p}}
$$

and for the heated plate facing down as

$$
h_{c x}^{0, d}=\frac{0.82 \cdot(G r \cdot \operatorname{Pr})^{1 / 5} \cdot k_{p}}{H_{p}}
$$

where the Grashof number is

$$
G r=\beta \cdot \Delta T \cdot g \cdot L^{3} / v^{2}
$$

where $L$ is the length of the surface. 
In Eq. (6) and (7), $h_{c y}$ is the average natural convection heat transfer coefficient for the vertical plate surface and is given by

$$
h_{c y}=h_{c y}{ }^{0} \frac{B_{h}}{\exp B_{h}-1}
$$

The heat transfer coefficient for zero mass transfer is

$$
h_{c y}{ }^{0}=\frac{0.68+0.67 \cdot(G r \cdot \operatorname{Pr} \cdot \varphi)^{1 / 4} \cdot k_{p}}{T H_{p}}
$$

For the experimental conditions, at steady state $\left(\mathrm{t} \sim 1840^{\circ} \mathrm{C}\right), \mathrm{Gr}$ is less than $10^{\circ}$. Laminar boundary layer occurs on the graphite plate surface. The Prandtl number function $\varphi$ is defined as

$$
\left.\varphi=[]+\left(\frac{0.492}{\operatorname{Pr}}\right)^{9 / 16}\right]^{-16 / 9}
$$

As a result of combustion, $3.28 \times 10^{7} \mathrm{~J} / \mathrm{kg}$ of heat is released. The mass transfer rates $m$ " are

$$
\begin{aligned}
& \dot{m}_{x}^{\prime \prime}=\eta_{x}{ }^{0} \cdot \frac{\ln \left(\mathrm{I}+\beta_{1 m}\right)}{\beta_{1 m}} \cdot \beta_{\mathrm{l} m} \\
& \dot{m}_{y}^{\prime \prime}=\eta_{y}{ }^{0} \cdot \frac{\ln \left(\mathrm{I}+\beta_{1 m}\right)}{\beta_{1 m}} \cdot \beta_{1 m}
\end{aligned}
$$

where $\frac{\ln \left(1+\beta_{1 m}\right)}{\beta_{1 m}}$ is the mass transfer blowing factor and $\beta_{l m}$ is the mass driving force. It is obtained as

$$
\beta_{1 m}=\frac{m_{1, e}-m_{1, s}}{m_{1, s}-n_{1, s} / m^{n}}
$$

where $m_{1, s}$ is the species 1 mass concentration on the surface of the graphite plate, denoting I as oxygen. Since the chemical kinetics are so rapid, the reaction is diffusion controlled. The gas mixture at the graphite plate surface is in the equilibrium with the solid carbon. The equilibrium data indicates that the concentration the oxygen at the surface is essentially zero. That is $m_{1, s}=0$. Where $m_{1, e}$ is the species concentration in the ambient air. It equals to 0.231 . The ratio between oxygen mass flux transferred to the graphite plate surface and the total mass transfer rate is $n_{1, r} / \dot{m}^{\prime \prime}$.

By using the analogy between heat and mass transfer, the zeromass-transfer-limit mass transfer conductance are

$$
\begin{aligned}
\eta_{x}{ }^{0, u} & =\frac{0.54 \cdot(G r \cdot S c)^{1 / 4} \cdot \rho \cdot D_{12}}{H_{p}} \\
\eta_{x}{ }^{0, d} & =\frac{0.82 \cdot(G r \cdot S c)^{1 / 5} \cdot \rho \cdot D_{12}}{H_{p}}
\end{aligned}
$$

$$
\eta_{y^{\prime}}{ }^{0}=\frac{0.68+0.67 \cdot\left(G r \cdot S_{c} \cdot \varphi\right)^{1 / 4} \cdot \rho \cdot D_{12}}{T H_{p}}
$$

where $D_{12}$ is the binary diffusion coefficient.

\subsection{Numerical model for the heat flux gage}

The heat flux gage is represented by a solid copper block of diameter (i.e., height in the 2-D model), $\mathrm{D}$, and thickness, $\mathrm{TH}_{\mathrm{z}}$, as shown in figure 5 . Boundary conditions on the front face and upper and lower surfaces are free convection of air and radiation. Forced convection of water is the boundary condition on the back face. The two dimensional governing energy equation for the heat flux gage is

$$
\frac{\partial}{\partial x}\left(k_{g} \frac{\partial T}{\partial x}\right)+\frac{\partial}{\partial y}\left(k_{g} \frac{\partial T}{\partial y}\right)=0
$$

where $k_{g}$ is the thermal conductivity of the gage.

The boundary conditions are:

$$
\begin{gathered}
y=D \quad ; \quad-k_{g} \frac{\partial T}{\partial y}=h_{c x g}{ }^{\prime \prime} \cdot\left(T-T_{e}\right) \\
y=0 \quad ; \quad-k_{g} \frac{\partial T}{\partial y}=h_{c x g}{ }^{d} \cdot\left(T-T_{e}\right) \\
x=0 \quad ; \quad-k_{g} \frac{\partial T}{\partial x}=q_{g}+h_{c y g} \cdot\left(T-T_{e}\right) \\
x=T H_{g} ; \quad-k_{g} \frac{\partial T}{\partial x}=h_{\text {water }} \cdot\left(T-T_{\text {water }}\right)
\end{gathered}
$$

The convective heat transfer coefficients $h_{c x g}$ and $h_{c y g}$ are given by substituting $D$ for $H_{p}$ in Eq. (15) and substituting $\mathrm{TH}_{\mathrm{s}}$ for $\mathrm{TH}_{\mathrm{p}}$ in Eq. (12) and Eq. (13), respectively.

In a manner similar to $q_{p}, q_{g}$ is the net radiation heat transfer out of the gage surface. It is also obtained by including two parts which are

$$
\begin{gathered}
q_{g p}=\frac{\sigma \cdot \varepsilon_{g} \cdot T_{g}^{4}-\sigma \cdot \varepsilon_{p} \cdot T_{p}^{4}}{\frac{1-\varepsilon_{p}}{\varepsilon_{p} \cdot A_{p}}+\frac{1}{A_{g} \cdot F_{g p}}+\frac{1-\varepsilon_{g}}{\varepsilon_{g} \cdot A_{g}}} \\
q_{g a}=\left(1-F_{g a}\right) \cdot \sigma \cdot \varepsilon_{g} \cdot\left(T_{g}^{4}-T_{a}^{4}\right)
\end{gathered}
$$

where $q_{g p}$ and $q_{g a}$ are the net radiation heat flux as from heat flux gage to the graphite plate and ambient surroundings, respectively.

Forced convection cooling occurs due to water flow over the back face of the gage substrate. Water comes in the tube 1 on one side of the gage, circles around the channel inside the gage and then leaves from the tube on the other side of the gage. The inlet water temperature is $25^{\circ} \mathrm{C}$. The water velocity $\mathrm{V}$ is assumed to be $-1 \mathrm{~m} / \mathrm{s}$. Reynold number corresponding to this velocity is approximately $9 \times 10^{4}$. Thus, for turbulent flow the heat transfer coefficient, $h_{\text {warer }}$, is obtained as 


$$
h_{\text {water }}=\frac{0.023 \cdot \operatorname{Re}^{0.8} \cdot \operatorname{Pr}^{0.4} \cdot k_{\text {water }}}{D I}
$$
5.

Where DI is the inside diameter of the channcl as shown in Fig.

\subsection{Erosion Calculation}

During the heating of the graphite plite, there is chemical reaction which involves burning carbon in the air. The reaction is $\mathrm{C}+\mathrm{O}_{2}=\mathrm{CO}_{2}$. Since carbon is continuously consumed at the plate surface, the thickness and the width of the graphite plate decreases with time. A simplification is made in the model by assuming that each point on the plate surface undergoes the same average erosion. As a result, the shape of the graphite plate for proposes of computation always remains square whereas the actual plate assumes a tapered shape.

The mass balance on the graphite plate surfice is

$$
\frac{d}{d t}\left(V \cdot \rho_{p}\right)=-\dot{m}^{\prime \prime} \cdot A
$$

where $\rho_{p}$ is the density of the graphite plate. The volume of the graphite plate, $\mathrm{V}$, is equal to $L_{p} \cdot H_{p} \cdot T H_{p}$ and the surface area $\mathrm{A}$ of one side of the plate and is equal to $L_{p} \cdot H_{p}$. Thus the rate of decrease of the thickness is obtained as

$$
\frac{d}{d t}\left(T H_{p}\right)=\frac{\dot{m} "}{\rho_{p}}
$$

\subsection{Calculation Procedure}

Due to erosion, the shape of the graphitc plate changed with time. Yet, based on the experiment, the plate temperature doesn't change rapidly, such that at each erosion time step (one second), the temperature is quasi steady. In carrying out the numerical calculations, at each erosion time step, the following steps were used:

1. Give the initial temperature of the graphite plate and the heat flux gage.

2. Apply boundary conditions to every equation and obtain new temperature.

3. Use the graphite plate new temperature in the radiation boundary condition of heat flux gage, update temperature of the heat flux gage and use it for the radiation boundary condition of graphite plate. value.

4. Repeat step 2 onwards until the results converge to a unique

5. From the erosion rate of the graphite plate, calculate the shape change due to combustion and thereafter obtain the ncw shape factor between the graphite plate and the heat flux gage to be used for the next time step.

6. Repeat from step 2 to step 5 until the final time.

\section{RESULTS AND DISCUSSIONS}

Comparison is made between the experimental data and the numerical calculations. Discussion of the results will include temperature distribution, heat flux, graphite plate erosion, grid sensitivity, and possible reasons for errors between the experimental data and numerical calculations.

\subsection{Temperature distribution}

The temperature distribution in the graphite plate and the heat flux gage, as computed from the numerical model, are shown in Fig. 7. The results shown in Fig. 7 were computed at test time $=60$ seconds, the initial time in the analysis. The measured surface temperature at the vertical center of the graphite plate was $2066 \mathrm{~K}$. This temperature is about $4 \%$ higher than that predicted from the numerical calculation ( $1986 \mathrm{~K})$.
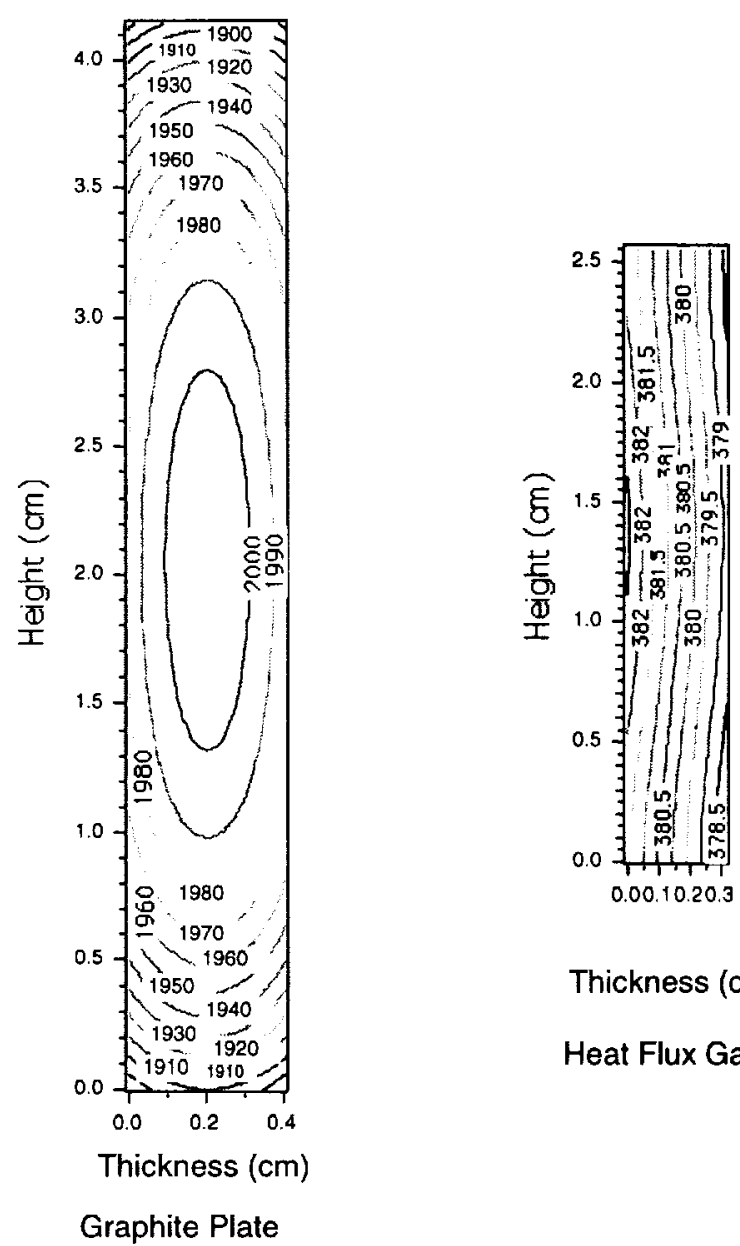

Thickness $(\mathrm{cm})$

Heat Flux Gage

Figure 7: Graphite Plate and Heat Flux Gage Temperature Distribution 


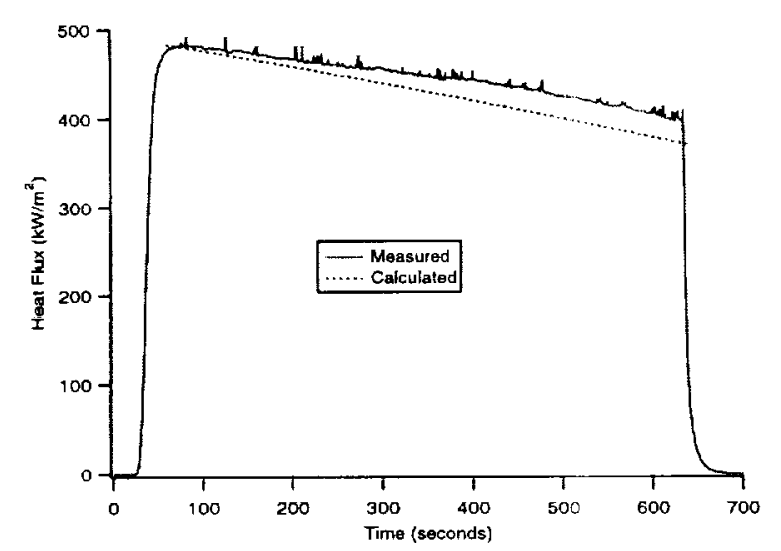

Figure 8: Comparison of Experimental and Numerical Calculated Gage Heat Flux

\subsection{Heat flux}

Given a nominal experimental condition for heat flux of 477 $\mathrm{kW} / \mathrm{m}^{2}$, applied for $10 \mathrm{mins}$, a comparison is made between the measured heat flux vs time and the numerical heal llux vs time. Due to the combustion, the graphite plate become thinner and thinner. The net radiation heat flux from the graphite plate reaching the gage decreases with time as shown in Fig. 8. The difference between the experimental and numerical prediction is less than $7 \%$.

\subsection{Graphite plate erosion}

Since the combustion of the carbon occurs at the surface of the graphite plate, carbon is burned into $\mathrm{CO}_{2}$, and the plate become thinner with time. It was found that in 10 minutes, the height of the plate decreased from $4.14 \mathrm{~cm}$ to the final measurement $3.8 \mathrm{I} \mathrm{cm}$ whereas the initial thickness decreased from $0.406 \mathrm{~cm}$ to $0.282 \mathrm{~cm}$. Both of the experimental and the numerical results are shown in Fig. 9.

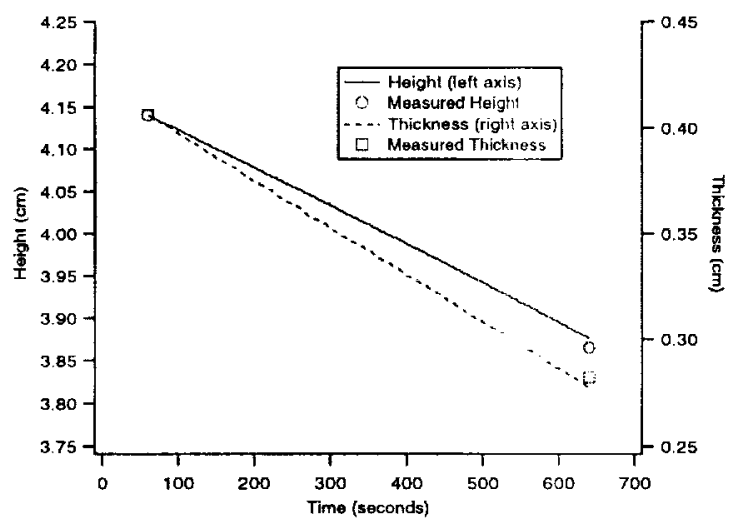

Figure 9: Change of the Graphite Plate Height and Thickness

\subsection{Grid sensitivity}

The numerical model described in section 3 was first tested for its accuracy by comparing the calculated gage heat flux with the experimental data using the $5 \times 5$ mesh size. The error was $\sim 5 \%$. For testing the grid resolution, the computations were made by using the mesh densities from $7 \times 7$ to $107 \times 107$. The numerical results are plotted in Fig. 10. From Fig. 10, it can be seen that as the number of mesh points increase, the heat flux decreases and is approaching an asymptotic value for large number of mesh points. As the difference between the $37 \times 37$ and the asymptotic heat flux values is approximately $1 \%$, the computations in this study were performed with $37 \times 37$ mesh to save the computation time with sufficient accuracy of numerical result.

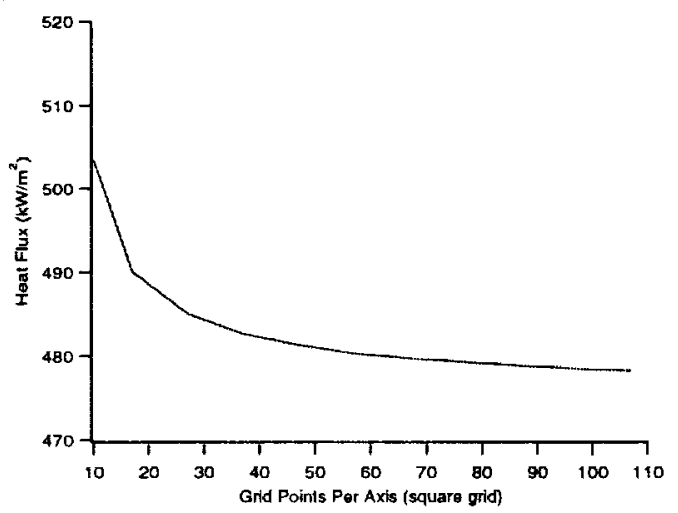

Figure 10: Grid Sensitivity

\subsection{Possible reasons for the discrepancies found between experimental results and numerical computations}

From the comparisons discussed in section $4.1,4.2,4.3$, several reasons for the difference between the numerical prediction and the experimental data are possible. These include

\section{Experiment error}

The various measurements taken during the course of the experiment have uncertainties associated with them. Sources of these uncertainties include the readings of the voltmeter, the current meter, and the voltage transducers, as well as the electric current measurement coil and the optical pyrometer.

The uncertainty estimates for various measurements are summarized in Table 1. The total uncertainty in a measurement is the square root of the sum of the squares of the component uncertainties. Uncertainties in the heat flux gage calibration are not included since the calibration system characterization project is attempting to define those uncertainties.

Uncertainties in the plate dimension measurements are as follows: $\pm 0.25 \mathrm{~mm}$ for thickness and $2.54 \mathrm{~mm}$ for height. A small, but unknown, amount of erosion occurs prior to the beginning of the analysis. This erosion occurs during a short heating of the plate to verify proper clamping of the plate and during the transient startup of each experimental run. 
Table 1: Experimental Measurement Uncertainty

\begin{tabular}{|c|c|c|c|c|}
\hline $\begin{array}{c}\text { Measurement } \\
\text { Source } \downarrow\end{array}$ & $\begin{array}{l}\text { Heat } \\
\text { Flux }\end{array}$ & $\begin{array}{c}\text { Plate } \\
\text { Current }\end{array}$ & $\begin{array}{c}\text { Plate } \\
\text { Voltag } \\
e \\
\end{array}$ & $\begin{array}{c}\text { Plate } \\
\text { Temperalure }\end{array}$ \\
\hline Voltmeter & $\begin{array}{l} \pm 0.1 \\
W / \mathrm{cm}^{2}\end{array}$ & $\begin{array}{l} \pm 0.4 \\
\text { Amp }\end{array}$ & $\begin{array}{c} \pm 0.009 \\
V\end{array}$ & \\
\hline $\begin{array}{r}\text { Current } \\
\text { Transformer }\end{array}$ & & $\begin{array}{l} \pm 24 \\
\text { Amp }\end{array}$ & & trty \\
\hline $\begin{array}{c}\text { Current } \\
\text { Transducer }\end{array}$ & & $\begin{array}{l} \pm 15 \\
A m p\end{array}$ & & 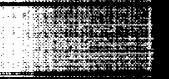 \\
\hline $\begin{array}{c}\text { Volt } \\
\text { Transducer }\end{array}$ & & & $\begin{array}{c} \pm 0.225 \\
V\end{array}$ & \\
\hline $\begin{array}{c}\text { Optical } \\
\text { Pyrometer }\end{array}$ & & & & $\pm 3^{\circ} \mathrm{C}$ \\
\hline $\begin{array}{c}\text { Total } \\
\text { Uncertainty }\end{array}$ & $\begin{array}{l} \pm 0.1 \\
W / \mathrm{cm}^{2}\end{array}$ & $\begin{array}{l} \pm 28.3 \\
A m p\end{array}$ & $\begin{array}{c} \pm 0.225 \\
V\end{array}$ & $\pm 3^{\circ} \mathrm{C}$ \\
\hline
\end{tabular}

Note: All source uncertainties are derived from manufacturers data.

\section{The effect of parameters}

The properties used in the numerical model came from a variety of sources. Material properties of the ATJ graphite were obtained from the material manufacturer. Properties for the copper block representation of the heat flux gage were taken from a handbook. Emissivity of the graphite plate and black paint which coated the heat flux gage face were obtained using an emissivity measuring optical pyrometer described by Matthews(1989). Mosi properties were obtained as functions of temperature. However, some properties, such as the emissivity of the paint on the gage face, coutd only be obtained for room temperature.

Errors are introduced into the numerical calculation since the manufacturer and handbook data represent typicil values as opposed to measurements for the actual pieces of material used. Properties known only at room temperature are likely to viry somewhat with temperature thereby introducing another error in (o) the calculation.

Electrical current passing through the plate is the primary energy source in the model and was obtained from masurements. These measurements have an uncertainty interval associnted with them. This uncertainty is another source of error in the numerical heat flux computation. Table 2 summarizes the effect variations in several parameters have on the numerical results.

Table 2: Heat flux changes caused the uncertainties of various parameters

\begin{tabular}{|l|l|l|l|l|l|}
\hline Emissivity & $\begin{array}{l}\text { Heat } \\
\text { Flux }\end{array}$ & Current & $\begin{array}{l}\text { Heat } \\
\text { Flux }\end{array}$ & $\begin{array}{l}\text { Thermal } \\
\text { Conductivity }\end{array}$ & $\begin{array}{l}\text { Heat } \\
\text { Flux }\end{array}$ \\
\hline \pm 0.1 & $11 \%$ & $\pm 24 \mathrm{Amp}$ & $4 \%$ & \pm 5 & $.04 \%$ \\
\hline
\end{tabular}

3. The limitation of the numerical model

In reality, the graphite plate shape varies in all the 3-dimensions. The incident heat flux can be estimated more accurately only when three-dimensional computation is performed. Also, cven for the 2-D model, the graphite plate burning rate would be difierent at different location on the surface since there is low mass trinsfer rate at the top of the plate, and high mass transfer rate at the holtom of the plate. Thus, the final shape of the cross section does not remain rectangular anymore and this can affect the shape factor then finally affect the estimation of the heat flux received by the gage.

The numerical analysis currently models the heat flux gage as a solid piece of copper. In reality, the circular foil heat flux gage used in the experiment has a far more complex structure. This simplification does not effect incident heat flux computations but will impact absorbed heat flux calculations. The heat flux data presented in this paper are incident heat flux. The detail of the actual heat flux gage will be incorporated into future versions of the numerical analysis.

\section{CONCLUSIONS}

A two-dimensional finite difference model of a flat plate heat flux gage calibration system has been developed. The numerical solution provides temperature distributions through the thickness of the flat plate heating element and the heat flux gage, the heat flux at the gage face, and the shape change of the flat plate with time. Initial grid refinement has been performed and has reduced grid error to less than $0.05 \%$ between successive grid sizes. Preliminary comparison to experimental data has also been performed. Differences between numerical and experimental data are less than $7 \%$.

Additional work needs to be performed in order to identify and quantify the effect of various error sources present in the calibration system. This work will incorporation of additional detail of the heat flux gage structure, and extension of the model to 3 dimensions. The numerical analysis will eventually be extended to uncooled heat flux gages operating at high $\left(850^{\circ} \mathrm{C}\right)$ temperature.

\section{REFERENCE}

Holmberg, D., K. Steckler, C. Womeldorf, and W. Grosshandler, 1997 "Facility for Calibrating Heat Flux Sensors in a Convective Environment", ASME International Mechanical Engineering Conference and Exhibition.

Grosshandler, William L. and Blackburn, D 1997, "Development of a High Flux Conduction Calibration Apparatus", ASME International Mechanical Engineering Conference and Exhibition.

Murthy, Annageri V., Benjamin K. Tsai, 1997, "Radiative Calibration of Heat Flux Sensors at NIST - an Overview", ASME International Mechanical Engineering Conference and Exhibition.

Matthews, E. K. and G. J. Kilford, 1989, "Operating Experience with an Emissivity Measureing Laser Based Infra-Red Pyrmeter", International Test and Tranducer Conference.

Patankar, S.V., 1984, "Numerical Heat Transfer and Fluid Flow", by Hemisphere Publishing Corporation.

Horn, T.J., 1993, "Comparison of Heat Flux Standard for Calibration Heat Flux Gage at elevated Temperature and High Heat Flux Levels", Master thesis 